\title{
"Matemática? Eu trabalho primeiro no concreto": elementos para a história do senso comum pedagógico
}

\author{
"Math? I work first with the concrete": \\ elements for educational history of pedagogical common sense
}

Wagner Rodrigues Valente ${ }^{1}$

\begin{abstract}
Resumo: O texto analisa um dos elementos presentes na cultura escolar do ensino de matemática nos primeiros anos escolares. Trata-se do senso comum pedagógico que indica como forma correta da docência nesse nível de ensino "trabalhar primeiro no concreto". A análise é realizada por meio de um estudo histórico tendo em conta artigos publicados por revistas pedagógicas na última década do século XIX. São considerados autores que têm os seus estudos voltados para a chamada História Cultural. Como resultado, verifica-se que "trabalhar primeiro no concreto" é herança pedagógica vinda do movimento pelo ensino intuitivo, vaga internacional que se constituiu em verdadeira contracultura pedagógica nas últimas décadas do século retrasado. Tal herança é reelaborada e chega aos dias atuais sobretudo a partir do uso de materiais didático-pedagógicos para o ensino do sistema de numeração decimal.
\end{abstract}

Palavras-chave: Ensino de matemática. História da educação matemática. Aritmética. Cultura escolar.

\begin{abstract}
The purpose of this paper is to analyze one of the elements present in the school culture of teaching math in the early school years: teaching common sense that indicates how correct the way of teaching is at this level of education ie "work first in the concrete." The analysis is performed by means of a historical study of published articles from pedagogical magazines in the last decade of the nineteenth century. Authors are considered who studied so-called Cultural History. As a result, it appears that "working first in the concrete" is the pedagogical heritage of the movement for intuitive teaching, an international movement that constituted a true pedagogical counterculture in the last decades of the last century. This heritage is redesigned and comes into its own today especially the use of didactic and pedagogical materials for education on the numbering system.
\end{abstract}

Keywords: Arithmetic. Primary school mathematics. History of mathematics education. School culture.

\footnotetext{
${ }^{1}$ Universidade Federal de São Paulo (Unifesp), Escola de Filosofia, Letras e Ciências Humanas, Departamento de Educação, Guarulhos, SP, Brasil. E-mail: <wagner.valente@unifesp.br>.
} 


\section{Introdução}

Muitos são os estudos que tomam por tema o "ensino no concreto". Essa expressão, bem como outras derivações dela - ensino concreto, ensino pelo concreto, concretização, trabalho no concreto, material concreto - parece designar, no cotidiano das escolas, algo como uma reação, ou mesmo uma aversão à abstração, sobretudo quando observamos relatos de professores dos primeiros anos escolares. E, neste caso, a abstração é considerada como algo fora da vida, do real. Assim, "eu trabalho primeiro no concreto", para usar expressão título de um desses estudos ${ }^{2}$, remete às práticas do professor que enlaça a realidade cotidiana para melhor desenvolver o seu ensino de matemática. Na verdade, e precisando melhor os dados, como ressalta o estudo de Nacarato (2005), a expressão "trabalhar primeiro no concreto" significa uma prática pedagógica que inclui o uso de materiais manipuláveis para ensinar matemática nos primeiros anos escolares.

"Eu trabalho primeiro no concreto" é assertiva do senso comum pedagógico. E, aqui, já se deveria caracterizar tecnicamente tal expressão: "senso comum pedagógico". Ela ganha nos estudos de muitos historiadores da educação a conceituação de "cultura escolar". Trata-se de um conjunto de normas de organização do trabalho pedagógico e práticas específicas que atendem às finalidades da escola num dado tempo histórico ${ }^{3}$. Ensinar primeiro no concreto, então, é ingrediente da cultura escolar.

É intenção deste estudo problematizar esse elemento da cultura escolar. Como "trabalhar primeiro no concreto" passou a fazer parte da cultura escolar para os ensinos de matemática? Como a expressão ganhou o significado de ensino com o uso de materiais concretos? Tais questões, amplas, necessitam de escolhas para serem respondidas. Uma dessas escolhas diz respeito à eleição de um tema da matemática, no qual é tomado o “ensino concreto". No caso dos primeiros anos escolares, tal decisão parece não constituir dificuldade quando se aborda o cálculo, a aritmética desse nível de ensino. Considere-se, pois, a aritmética escolar do curso primário. Outra escolha a considerar refere-se às fontes de pesquisa. Que documentos deverão ser mobilizados para investigar a penetração do "ensino concreto"? Aqui, o desafio é maior, pois há uma gama enorme de possibilidades a serem mobilizadas como fontes de pesquisa: textos oficiais que emanam diretivas de ensino; livros didáticos utilizados por professores; documentação de arquivos escolares; revistas pedagógicas que dão orientações para a prática pedagógica, entre outros. Dentre essas possibilidades e da atual etapa de desenvolvimento da pesquisa, que se encontra em etapa de análise dos levantamentos realizados em periódicos educacionais, neste texto optou-se por considerar como fontes para a investigação, as revistas pedagógicas.

\footnotetext{
${ }^{2}$ Leia-se o texto de Nacarato (2005). Para além desse estudo, há outros que abordam a mesma temática como, por exemplo, o trabalho de Maia (2001) e a pesquisa de Grando (1999), dentre muitos trabalhos.

${ }^{3}$ Para um estudo mais extenso relativamente à importância de se tomar "cultura escolar" como categoria de análise para estudos do meio escolar, vejam-se autores considerados já clássicos como Julia (2001) e Chervel (1990).
} 
Por certo as revistas pedagógicas constituem documentos relevantes para a análise das orientações veiculadas aos professores num dado tempo por autoridades do ensino, por especialistas da Educação e mesmo pelos próprios professores, dentre outros autores que escrevem nesses periódicos. Não é intenção deste texto discorrer sobre a importância delas, já há muito ressaltada em pesquisas de historiadores da educação ${ }^{4}$. Em síntese, esses periódicos "fazem circular informações sobre o trabalho pedagógico e o aperfeiçoamento das práticas docentes, o ensino específico das disciplinas", dentre outros temas (CATANI, 1996, p. 117). O objetivo deste estudo é analisar, em específico, as orientações didático-pedagógicas para o ensino de aritmética nos primeiros anos escolares presentes nesses periódicos nos finais do século retrasado e início do século XX, com o fim de encontrar pistas para compreender como "ensinar primeiro no concreto" passa a fazer parte da cultura escolar. A eleição desse recorte temporal justifica-se por levar em consideração o impacto das ideias de modernização pedagógica vindas com a vaga internacional do ensino intuitivo. Em meio a esse contexto, uma nova questão, um tanto mais específica que a colocada anteriormente, pode ser enunciada como: Que orientações aos professores estão presentes na última década do século XIX sobre o como ensinar aritmética no curso primário? Tal questão, também ampla, no decorrer do estudo ganha mais especificidade com a análise do material empírico. A análise revela que diferentes temas são abordados nas orientações didático-pedagógicas. E um dos temas é o da "concretização". Os discursos direcionados aos professores, as lições-padrão e toda sorte de escritos publicados nas revistas pedagógicas empreendem verdadeira tarefa de catequese dos mestres para novas práticas pedagógicas. Elas envolvem a ruptura com o que é considerado um modo antigo, tradicional de tratar os ensinos, buscando convencer os docentes de que a moderna pedagogia impõe a "concretização" no ensino de aritmética para os primeiros anos escolares. Essa é uma das faces reveladas nas orientações para professores que ensinam matemática em tempos da vaga pedagógica do ensino intuitivo. Assim, este estudo intenta percorrer textos publicados nas revistas pedagógicas com vistas a analisar como foi sendo construída, para a prática docente, a representação ${ }^{5}$ da necessidade de "trabalhar primeiro no concreto", no que diz respeito ao ensino da aritmética dos primeiros anos escolares. Em assim fazendo, acredita-se ser possível reunir elementos para compreensão de como "trabalhar primeiro no concreto" passou a fazer parte do senso comum pedagógico contemporâneo, isto é, da cultura escolar hoje.

Reitere-se: o objetivo do estudo é analisar, por meio de revistas pedagógicas, como "trabalhar no concreto" passou a fazer parte do senso comum pedagógico, incorporando-se à cultura escolar do ensino de aritmética nos primeiros anos escolares.

Por certo, penetrar no âmbito de uma cultura para compreender o significado que as suas representações têm, orientando as práticas dos sujeitos que dela participam, é algo complexo. Em A bistória cultural:entre práticas e representações (CHARTIER, 1990), talvez uma das

\footnotetext{
${ }^{4}$ Leiam-se, por exemplo, estudos já clássicos, organizados por Catani e Bastos (1997).

${ }^{5}$ E, neste ponto, mobiliza-se uma categoria da História Cultural: o conceito de representação: “o modo como em diferentes lugares e momentos uma determinada realidade social é construída, pensada, dada a ler" (CHARTIER, 1990, p. 16-17).
} 
obras mais conhecidas e citadas por pesquisadores da história da educação no Brasil, Roger Chartier, seu autor, desde o título parece já tentar esclarecer do que trata o ofício do historiador cultural: um trabalho que se situa "entre práticas e representações". Para chegar a essa síntese, Chartier paulatinamente leva o leitor de considerações amplas sobre a escrita da história e a sua transformação ao longo dos últimos tempos para os conceitos e ferramentas intelectuais necessários ao entendimento da problemática do "mundo como representação". Assim é que na Introdução de sua obra, Chartier menciona como pensa a história cultural e conceito de representação: "A história cultural, tal como a entendemos, tem por principal objeto identificar o modo como em diferentes lugares e momentos uma determinada realidade social é constituída, pensada, dada a ler" (CHARTIER, 1990, p. 16-17). Ou escrito de outro modo: cabe à história cultural a análise das representações.

\section{A vaga intuitiva, um movimento pedagógico mundial}

O final do século XIX assiste à emergência de uma verdadeira contracultura pedagógica. Muito antes disso, a Educação tem referências que apontam para a não coerção dos alunos, para um modo diferenciado de conduzir a criança a seu estado adulto. Rousseau, Pestalozzi, Fröebel são autores que inspiram essa contracultura pedagógica. E, por volta de 1880, em circuito internacional, alastra-se a vaga intuitiva como forma moderna de tratar as questões educacionais ${ }^{6}$. Contra uma cultura estabelecida de considerar o homúnculo - a criança como homem em miniatura - assentando-se na ideia de que a criança é um ser diferente, alguém que está em processo de formação e tem estágios evolutivos. Contra um modo considerado antinatural de imposição e coerção de padrões e mesmo de violência física. Contra uma cultura chamada livresca, baseada em processos de memorização. Enfim, estabelece-se uma contracultura pedagógica. E essa contracultura pedagógica se faz método: Método intuitivo - lição de coisas - como tal época é interpretada no Brasil ${ }^{7}$.

De modo mais específico, no âmbito dessa contracultura, os saberes escolares e seu modo de tratamento refletirão uma nova maneira de pensar a Educação. Os processos de memorização, combatidos, referiam-se ao saber considerado livresco: o saber escolar, colocado nos livros, expressava graus de abstração, de sistematização que, mediante a necessidade de ser apropriado pelos alunos, levava à memorização. À cultura estabelecida, não haveria outro modo para os iniciantes aproximarem-se do saber sistematizado nos livros, que não fosse por

\footnotetext{
${ }^{6} \mathrm{Um}$ estudo interessante e aprofundado sobre o tema pode ser lido na obra de Pierre Kahn, intitulada La leçon de choses: naissance de l'enseignement des sciences à l'école primaire, em especial, e particularmente, o item Géopédagogie de la leçon de choses (KAHN, 2002).

${ }^{7}$ Uma referência importante para o período diz respeito à tradução, adaptação e grande circulação que teve o livro Primeiras lições de coisas, de Norman Allison Calkins, por Rui Barbosa, em 1886. A tradução da obra, dentre outras coisas, vem fundamentar a tese defendida por Rui de que "lição de coisas" é um método e não uma matéria independente do programa escolar (BARBOSA, 1946, p. 215-216).
} 
processos de memorização. E essa sistematização dos saberes, colocada nos livros, propunha sempre que os primeiros passos a serem dados em direção aos saberes mais avançados devessem ser encadeados numa ordem lógica. Essa ordem levaria os alunos dos simples elementos de um saber aos seus termos mais complexos.

Tudo muda, no entanto, na perspectiva de uma nova cultura pedagógica. Os métodos que lançam mão da memorização devem ser abandonados em favor de métodos em que haja uma participação mais ativa do aluno. A psicologia nascente passa mais e mais a respaldar argumentos de que é necessário seguir o desenvolvimento do aluno, na sua ordem natural, para que o ensino possa ser eficiente. E essa ordem natural aponta para a intuição sensível da criança. É preciso considerar que a primeira forma de conhecimento é intuitiva.

Circulam internacionalmente propostas de ensino intuitivo de todas as matérias escolares $^{8}$. E, por certo, os ensinos de aritmética não ficaram imunes a essa vaga intuitiva.

\section{Orientações sobre o como ensinar, lidas em que revistas?}

Como se menciona anteriormente, este estudo privilegia a leitura e análise das revistas pedagógicas com o fim de problematizar o que hoje está presente na cultura escolar como "trabalho primeiro no concreto". No texto das revistas, analisam-se as orientações didático -pedagógicas que intentam levar os professores a fazerem parte da modernidade pedagógica trazida pela vaga pedagógica do ensino intuitivo.

A empiria que dá sustento à escrita deste texto é tomada do Repositório de Conteúdo Virtual ${ }^{9}$. Trata-se de base de dados aberta na internet, alimentada por diferentes estados e grupos de pesquisa brasileiros com documentação basilar para a história da educação matemática.

Assim, os artigos de revistas são selecionados numa busca no Repositório ${ }^{10}$. Atentase para aqueles artigos cujo tema é o ensino de aritmética, publicados a partir de 1880, época considerada como início da vaga intuitiva internacional ${ }^{11}$. A entrada na base de dados considera os periódicos por ordem cronológica, analisando um a um, seja utilizando os metadados de cada documento - quando existentes de modo satisfatório -, seja por análise direta das páginas de cada revista. Há poucas publicações em finais do século XIX de periódicos pedagógicos. Encontram-se textos significativos vindos da antiga capital (Salvador, Bahia), da Capital Federal (Rio de Janeiro) e de São Paulo, estado enriquecido pelo café e construtor de modelos de organização do curso primário adotado por todo o país. Tal processo e grade seletiva levam aos artigos, autores e periódicos apresentados no Quadro 1.

\footnotetext{
${ }^{8}$ Ver Kahn (2002).

${ }^{9}$ Disponível em: < https://repositorio.ufsc.br/handle/123456789/1769>. Acesso em: 27 jun. 2017.

${ }^{10}$ De fato, cabe informar que o uso do Repositório, na escolha das revistas, levou inicialmente em conta o mapeamento das revistas brasileiras elaborado por Catani (1996).

${ }^{11}$ Ver Kahn (2002).
} 
Quadro 1. Lista de artigos

\begin{tabular}{|l|l|l|}
\hline Ano & \multicolumn{1}{|c|}{ Título do artigo e autor } & \multicolumn{1}{c|}{ Periódico } \\
\hline 1892 & $\begin{array}{l}\text { Editorial. } \\
\text { Argemiro Cavalcante }\end{array}$ & Revista do Ensino Primário, [Salvador], v. 1, n. 1, nov. \\
\hline \multicolumn{2}{|l|}{ Disponível em: <https://repositorio.ufsc.br/handle/123456789/129725>. Acesso em: 27 jun. 2017} \\
\hline $\mathbf{1 8 9 3}$ & $\begin{array}{l}\text { Observação aos professores ou } \\
\text { adjuntos que se occupam do } \\
\text { ensino de arithmetica... } \\
\text { J. F. Velho da Silva }\end{array}$ & Revista Pedagógica, [Rio de Janeiro]. \\
\hline
\end{tabular}

Disponível em: < https://repositorio.ufsc.br/xmlui/handle/123456789/130209>. Acesso em: 27 jun. 2017

1893 O ensino de arithmetica I $\quad$ Revista do Ensino Primário, [Salvador], v. 1, n. 8, jun. Pedro Celestino

Disponível em: <https://repositorio.ufsc.br/xmlui/handle/123456789/129730>. Acesso em: 27 jun. 2017

\begin{tabular}{|c|c|c|}
\hline & $\begin{array}{l}\text { Arithmetica elementar } \\
\text { Oscar Thompson }\end{array}$ & A Eschola Publica, São Paulo, v. 1, n. 1, jul. \\
\hline
\end{tabular}

Disponível em: <https://repositorio.ufsc.br/xmlui/handle/123456789/133603>. Acesso em: 27 jun. 2017

1893 O ensino de arithmetica III $\quad$ Revista do Ensino Primário, [Salvador], v. 1, n. 11, set. Pedro Celestino

Disponível em: <https://repositorio.ufsc.br/xmlui/handle/123456789/129733>. Acesso em: 27 jun. 2017

1893 O ensino de arithmetica IV $\quad$ Revista do Ensino Primário, [Salvador], v. 1, n. 12, out. Pedro Celestino da Silva

Disponível em: <https://repositorio.ufsc.br/xmlui/handle/123456789/129734>. Acesso em: 27 jun. 2017

\begin{tabular}{|c|c|c|}
\hline 1902 & $\begin{array}{l}\text { Cartas de Parker para o ensino } \\
\text { de arithmetica nas escolas } \\
\text { primárias } \\
\text { Joaquim Luiz de Silva Brito }\end{array}$ & Revista de Ensino, São Paulo, v. 1, n. 1, abr. \\
\hline
\end{tabular}

Fonte: Repositório Institucional da Universidade Federal de Santa Catarina. Disponível em: <https://repositorio. ufsc.br/xmlui/>. Acesso em: 27 jun. 2017.

A análise dos artigos que envolvem orientações didático-pedagógicas sobre como ensinar aritmética nos primeiros anos escolares, veiculadas nos periódicos, permite verificar, como se disse anteriormente, a presença de diferentes temas de orientação do professorado do ensino primário relativamente ao ensino de aritmética. E, em cada um desses temas, essas orientações constroem representações que deverão ser apropriadas pelos docentes, orientando 
as suas práticas ${ }^{12}$. Este texto, reitere-se, em outras palavras, atém-se à análise das orientações que buscam convencer o professorado que o melhor ensino da aritmética nos primeiros anos escolares está relacionado diretamente à necessidade de "trabalhar primeiro no concreto".

\section{Construindo a representação de "trabalhar primeiro no concreto"}

Um primeiro momento que se revela crucial relativamente às orientações didático-pedagógicas veiculadas pelos periódicos compreende a última década do século XIX. E é tal época que ganha ênfase neste texto. Destaque-se, de início, o texto assinado por Argemiro Cavalcante, em Editorial na Revista do Ensino Primário, impressa na Bahia ${ }^{13}$. O autor embate-se contra os livros didáticos chancelados pelo Conselho de Ensino baiano, considerando-os inadequados em face das novas orientações didático-pedagógicas:

Não comprehendemos a sympathia que inspira ao Conselho os desconhecidos auctores das cartas de A B C e das taboadas; porem, se foi condescendencia para com seus editores, esta é prejudicial a infância do Estado e aos creditos de sua instrucção. Temos uma lei que determina que o ensino deve ser pratico e intuitivo, e a adopção destes livros anti-pedagogicos não satisfaz aos requisitos impostos pela lei. [...]. O ensino d'estas disciplinas, como de todas as mais, deve ser do simples para o composto, do indifinido - para o definido, do concreto para o abstracto. Considerado este principio como verdade essencial dilatada pela psychologia abstaracta, (a) claro está que não devem ser admitidas as taboadas e as cartas de A B C nas escholas supraditas. (CAVALCANTE, 1892, p. 6).

Especificamente sobre as orientações para o ensino de aritmética, Cavalcante defende a seguinte posição:

O ensino de arithmetica que tem por base o calculo mental, que exerce grande influencia sobre a formação das idéas e sobre as faculdades intellectuaes, desenvolvendo o raciocinio deductivo, deve ser feito por meio de exercicios praticos, analagos as lecções de cousas por meio de exercicios de

\footnotetext{
${ }^{12}$ A preocupação com a recepção e com o uso das representações levou Roger Chartier a lançar mão de outro conceito-chave para a história cultural: o conceito de apropriação. Será por meio dessa categoria dada a possibilidade de compreensão de como se dão os processos criativos de consumo das representações. Para o autor "a apropriação [...] tem por objetivo uma história social das interpretações, remetidas para as suas determinações fundamentais (que são sociais, institucionais, culturais) e inscritas nas práticas específicas de quem as produzem (CHARTIER, 1990, p. 26).

${ }^{13}$ A Revista do Ensino Primário foi criada por professores de escolas públicas primárias do estado da Bahia três anos depois da República. Para Santana (2009, p. 1), “além de representar um diagnóstico da educação, os textos refletem a tensão entre políticas públicas para a construção de um sistema de educação no Estado e as dificuldades para expandir a escola na Primeira República".
} 
calculo oral, com auxilio de quantidades concretas. Disse um pedagogista que: “a creança não entenderá a explicação mais elementar das regras da arithmetica, e mesmo a concepscão de numero, si não tiver previamente operado sobre objectos materiaes. A ideia de numero não diz nada ao espirito da creança, si tal ideia não fôr materialisada em alguma cousa que ella possa ver a apalpar: 3 não significa cousa alguma para ella, ao passo que 3 maçãs é muito clara". (CAVALCANTE, 1892, p. 8, grifo do autor).

É possível ler nessas linhas anteriores o embate, sobretudo, considerando-se o uso da tabuada. Ingrediente presente desde tempos longínquos no cotidiano escolar, a prática da tabuada envolve, especialmente, a memorização. Justamente a memorização é expediente condenado nas novas orientações, na pedagogia moderna que intenta impor-se nesse final de século XIX. A reação expressa em Editorial representa o alerta para a necessidade da concretização que deverá fazer frente ao ensino que apela para a memória, considerado ultrapassado pela vanguarda que escreve aos professores por meio da Revista do Ensino Primário.

Segue-se, a esse primeiro texto selecionado, a publicação vinda da Revista Pedagógica - publicação mensal do Pedagogium ${ }^{14}$, Rio de Janeiro - apresentando 20 lições para serem utilizadas pelos professores primários para o ensino da Aritmética, com as operações de somar e subtrair. As lições foram elaboradas por J. F. Velho da Silva, que assina a matéria e data as suas propostas de julho de 1893. O texto tem por título "Observação aos professores ou adjuntos que se ocupam do ensino da Arithmetica nas classes elementares das escolas de $1^{\circ}$. grau”. Logo ao princípio do texto, o autor pondera:

O espirito da criança é muitissimo concretisador e é por isso que o professor deve tomar interesse em que os objectos empregados sejam conhecidos pelas crianças. Qualquer que seja a materia a estudar, o concreto precede, deve preceder ao abstracto, na ordem natural das cousas, por esta razão deve o professor ou professora induzir menino ou menina a fazer toda a sorte de combinações e a conhecer todas as propriedades dos numeros, servindo-se do uso de objectos communs. (SILVA, 1893, p. 287, grifo do autor).

O tema da concretização neste artigo incide sobre a necessidade de o ensino acompanhar o desenvolvimento considerado natural da criança. Trata-se de momento de sedimentação das etapas pelas quais a criança passa na aprendizagem. E a primeira etapa refere-se ao concreto,

\footnotetext{
${ }^{14}$ De acordo com Fernandes (2013, p. 2-3) “a Revista Pedagógica fez parte do projeto de educação nacional posto em prática a partir da implantação da República, em 1889. Inseria-se numa das finalidades (no caso a publicação de uma revista) do Pedagogium - Museu Escolar do Distrito Federal, órgão criado em 1890, no âmbito da reforma educacional realizada por Benjamin Constant. Tal Museu havia sido criado com o objetivo de contribuir para o avanço da instrução, o qual deveria se constituir em lugar de referência, à semelhança do que já ocorria em outros países, encarados como mais avançados e, por isso, modelos a serem seguidos".
} 
ao uso de objetos concretos (empíricos) pelos professores em suas aulas de aritmética. Aqui, neste texto, do mesmo modo que no artigo citado anteriormente, conjugam-se e articulam-se uma concepção evolutiva do pensamento da criança que partirá sempre do "concreto", o que deverá levar o trabalho pedagógico do professor a acompanhar esse processo, "trabalhando no concreto".

No mesmo ano da publicação carioca, novamente o periódico baiano divulga orientações na direção da "concretização" necessária ao ensino da aritmética nos anos iniciais. E, nesse caso, há uma proposta sobre o modo como isso deverá ser conduzido. Em texto assinado pelo professor Pedro Celestino - que irá publicar vários outros artigos, aprofundando a temática -, a Revista do Ensino Primário faz saber aos professores como concretizar o ensino de aritmética nos primeiros anos.

É evidente o abuso dannoso das abstrações e decorações que a rotina inveterada tem exhibido para o ensino exclusivo de tão importante materia, longe de diminuir, parece que tende a prolongar-se em nossas escolas, attento a existencia dos velhos methodos, que de todos condemnados, entre nós encontram guarida e conservação. D'ahi, o nenhum melhoramento votado [sic] ao ensino do cálculo, apezar das successivas reformas porque tem passado a instrucção publica d'este estado. [...]. De tudo quanto levamos dito, vê-se que uma reforma nos processos do ensino do calculo se impõe nas circumstancias actuaes, como medida urgente, inadiavel e imprescindivel. [...] A reforma no nosso entender deve começar, pois, por ser introduzido em nossas escolas um contador mechanico ou outro qualquer meio material que auxilie a concretibilidade dos exercicios numericos. Sem estes instrumentos que julgamos indispensaveis a qualquer escola primária, que tiver pretenção a foros de boa, impossivel será ao professor dar aos seus alumnos idéa clara, exacta e correcta dos numeros. (CELESTINO, 1893a, p. 154-155).

Por certo, as preocupações sobre o ensino, sobre o modo como os professores devem conduzir um ensino concreto motivam a escrita acima. Não basta, pelo visto, apenas advogar que há necessidade de concretização. É preciso aparelhar a escola com materiais por intermédio dos quais o professor possa realizar o ensino concreto. O contador mecânico é um exemplo disso ${ }^{15}$. Assim, já desde o início, surgem os materiais para o "ensino concreto". Eles situam-se na linha evolutiva que desembocará cerca de meio século depois, nos materiais estruturados que buscarão apoio nos desenvolvimentos teóricos de Jean Piaget e a psicologia genética.

Nesse mesmo ano de 1893, no número de lançamento da revista A Eschola Publica ${ }^{16}$ de São Paulo, seu Editorial bem caracteriza o papel do periódico:

\footnotetext{
${ }^{15}$ Pais e Freitas (2015) têm interessante estudo que trata, dentre outros materiais, do contador mecânico. ${ }^{16}$ A Eschola Publica circulou em São Paulo no período de 1893 a 1897. "Essa revista mostrou-se como uma publicação emblemática para o período ao qual ela está circunscrita, período este rico na História do Brasil, marcado por acontecimentos que alteraram significativamente a estrutura social, política e econômica e assolado por uma efervescência de ideias educacionais (PINTO, 2008, p. 111- 112).
} 
Não promettemos artigos litterarios, nem scientificos: escreveremos o que pudermos, do modo que soubermos, tendo sempre em vista o alvo que miramos: velar pelas crianças, proporcionando aos professores públicos suggestões ao ensino, sugestões que a Eschola Normal não poude e nem poderá dar-lhes tão cedo. Em nossa folha daremos modelos de lições apropriadas a cada gráo do curso preliminar; transcreveremos, adaptando ao nosso meio entretanto, tudo o que de util encontrarmos nas nações estrangeiras; aproveitaremos todas as informações que nos ministrarem as escholas publicas da capital e do interior. (A ESCHOLA..., 1893, p. 1).

E, na mesma revista, no mesmo número, um artigo do professor Oscar Thompson ${ }^{17}$, intitulado Arithmetica elementar, reafirma a importância de "concretizar os números":

Outr'ora, crianças de tenra idade eram obrigadas, desde que entravam para a eschola, a decorar algarismos e taboadas, trabalho este que de nenhuma forma as entretinha e que muito cansava a sua memoria. Hoje envidam-se todos os esforços para tornar o ensino de tal materia attrahente de modo que leve a criança a mostrar-se desde as primeiras lições interessadas por elle. E o melhor meio para se obter esse desideratum é concretisar o estudo dos numeros. É preciso que a criança não considere os algarismos como meros symbolos, mas como grupos de objetos. (THOMPSON, 1893, p. 5).

Assim, a aritmética é constituída de símbolos. Símbolos que representam os objetos matemáticos. Objetos abstratos. Será preciso um ensino concreto. O ensino do sistema de numeração deve considerar imperativamente os objetos, as coisas, concretizar o processo levará a criança a interessar-se pela aritmética na escola. É o que advoga Thompson.

Ainda no ano de 1893, em novo número da Revista do Ensino Primário, tem-se outro artigo do professor Pedro Celestino. Esse autor escreve um conjunto de textos sobre o ensino de aritmética publicando-os desde o primeiro número da Revista. Sua intenção é a de mostrar aos professores como "concretizar o ensino". Faz isso apresentando uma série de materiais, dando destaque ao contador mecânico. Nesse número, publicado em setembro de 1893, destaca:

\footnotetext{
17 “Oscar Thompson teve um papel proeminente na instrução pública paulista nas duas primeiras décadas do século XX. Formado pela Escola Normal da Capital entre 1889 e 1891, iniciou a carreira no magistério primário na Escola Modelo do Carmo (anexa à Escola Normal) dirigida por Miss Browne em 1891. Em 1893 assumiu a direção dessa escola em substituição à diretora que se afastou temporariamente em viagem aos Estados Unidos. Em 1894, com o desdobramento das escolas-modelo anexas à Escola Normal de São Paulo, assume a direção da Segunda Escola Modelo permanecendo no cargo até 1897. Nesse período, formou-se bacharel em Ciências Sociais e Jurídicas pela Faculdade de Direito do Largo de São Francisco, em 1899. Entre 1901 e 1920 foi diretor da Escola Normal de São Paulo, afastando-se do cargo por duas vezes para assumir a Diretoria Geral da Instrução Pública: entre 1909 e 1911 e entre 1917 e 1920. Ao aposentar-se no magistério em 1920, Thompson continuou exercendo atividades em outros setores da administração pública” (SOUZA, 2009, p. 83).
} 
Agora que já fizemos um esboço geral da variedade destes instrumentos, sendo alguns de recente invenção, facil será julgar-se da sua utilidade, que cremos ter ficado assaz assentada. Julgamos escusado insistir mais sobre este ponto. $\mathrm{O}$ auxilio proveitoso que o methodo intuitivo pode tirar destes instrumentos, é bastante para dar uma idéa clara da sua importancia na arte de calcular, e por isso urge vulgarisal-os em nossas escolas, como meios indispensaveis à cultura preliminar do calculo. Entendemos que o contador mechanico substitue o melhor compendio, por tornar mais attrahente o ensino e de mais facil comprehensão os calculos a effectuar. Admittil-o em nossas escolas é dar o primeiro passo para libertar as creanças do habito funesto de calcularem automaticamente, é romper por uma vez com todas as velharias que obstruem o ensino moderno. Trata-se, como se vê, de um dos meios mais apropriados a execução do methodo intuitivo, que pela naturalidade, singeleza e amenidade da forma suggere, no espirito infantil, perfeita e nitida comprehensão das primeiras noções numericas assim explicadas. (CELESTINO, 1893b, p. 211-212).

Dessa forma, ao que parece, há nas observações do professor Celestino, de modo ainda inédito nas revistas analisadas, um discurso sobre o ensino de aritmética que faz relação direta entre a vaga pedagógica que atinge mundialmente a Educação - a vaga do ensino intuitivo- e a leitura desse movimento pedagógico no âmbito dos ensinos de aritmética para os primeiros anos escolares: a concretização dos números. E o professor Celestino esforça-se por mostrar aos mestres que o uso dos instrumentos do cálculo é o modo mais apropriado e eficaz de considerar a modernidade pedagógica, o ensino intuitivo, para a aritmética dos primeiros anos escolares. E esses instrumentos são múltiplos: Cartas de Parker, contadores ou aritmômetros, mapa mural do sistema métrico de Tanier, quadro de pesos e medidas métricas de Chardon, aparelhos de Level para o ensino intuitivo das unidades métricas, mapa mural do sistema métrico da sociedade americana Metric Bureau de Boston, quadro de pesos e medidas de C. Bopp, entre outros (CELESTINO, 1893b).

Desse modo, a necessidade de concretização dos números, considerada como forma didático-pedagógica que atende à modernização pedagógica de tratar os ensinos de modo intuitivo, deve munir-se de instrumentos, de suportes didáticos que permitem a concretização numérica.

Em 1902, o lançamento da Revista de Ensino - da Associação Beneficente do Professorado Público de São Paulo ${ }^{18}$ - faz eco à necessidade de incluir no cotidiano escolar, para as aulas de aritmética, equipamentos diferentes dos livros e compêndios didáticos. E, em meio a

\footnotetext{
${ }^{18}$ A Revista de Ensino constitui periódico criado pela Associação Beneficente do Professorado de São Paulo, tendo circulado no período 1902-1918. Segundo Catani, Vicentini e Lugli (1997, p. 82), nas páginas da revista "é possível acompanhar todas as questões que ocuparam o cenário educacional nos primeiros vinte anos do século, aqui no Brasil. Questões pertinentes à formação e às condições do trabalho docente, salário e carreira, bem como à estruturação das escolas e aos fundamentos das ciências da educação, se fizeram presentes nas produções da Revista de Ensino".
} 
tantas opções já estudadas pelo professor Celestino e divulgadas no periódico baiano, a Revista paulista faz circular, desde o seu primeiro número, e por vários números consecutivos, no item "Pedagogia Prática", as Cartas de Parker - para o ensino de arithmetica nas escolas primárias ${ }^{19}$. Apresentando a publicação, pode-se ler: "Em vista dos magnificos resultados por nós colhidos com o emprego das Cartas de Parker, no ensino de arithmetica em nossas escolas, e não haver á venda no mercado, julgamos prestar um relevante serviço aos colegas dedicados e a seus alumnos, publicando-as na nossa Revista”. (BRITO, 1902, p. 35).

O protagonismo de São Paulo em finais do século XIX no modo de organizar o curso primário e a formação de professores constitui base maior para explicar as razões da ampla circulação que teve o material Cartas de Parker. Outros estudos mostram como esse material circulou por muitos estados brasileiros. Mostram, ainda, a vida longa que esse dispositivo para o ensino de aritmética teve: praticamente meio século de existência ${ }^{20}$.

\section{Considerações finais}

O entendimento de uma construção cultural que se apresenta em tempos atuais em sua forma fenomênica exige retrospectiva por vezes longínqua e análise minuciosa de suas idas e vindas até que ela chegue a sedimentar-se numa dada norma ou prática. A análise dos elementos presentes na cultura escolar não é diferente. No âmbito de uma cultura não é permitida a avaliação de erro ou acerto, de lógica ou ilógica relativos ao que se constata nela, ao que dela faz parte. Reinam as apropriações. Será preciso interpretar os sentidos que uma norma ou prática têm no movimento de existência e transmissão dessa cultura, cultura escolar. "Eu trabalho primeiro no concreto" é exemplo disso. Refere-se a uma herança apropriada de tempos longínquos de embates vindos de uma contracultura pedagógica. Trata-se de uma representação. Ingrediente da cultura escolar.

O tema do "ensino primeiro no concreto" tem sido abordado por vários estudos na atualidade. Seja tratado de modo direto, seja por meio de pesquisas que envolvem formas alternativas do ensino de matemática como, por exemplo, os laboratórios de ensino de matemática. Ao que tudo indica, é em finais do século XIX que a cultura escolar incorpora o "ensino primeiro no concreto", tendo esse elemento presença até os dias de hoje. Um elemento da cultura escolar.

$\mathrm{Na}$ análise do impacto da vaga intuitiva, constrói-se a representação de que é preciso concretizar. Por certo, isso tem referência às lições que as coisas dão, às lições de coisas. Mas, a interpretação do "eu trabalho primeiro no concreto" segue da manipulação de objetos do mundo físico para representações desse mundo por meio de materiais didáticos.

\footnotetext{
${ }^{19}$ As Cartas de Parker constituem um dispositivo didático, inicialmente publicadas na Revista de Ensino e, posteriormente, transformadas em pranchas - cerca de 50 - para uso dos professores primários na condução das primeiras operações fundamentais da aritmética. Junto às pranchas, também conhecidas como Mapas, há orientações aos professores em cada uma delas. Para um estudo mais aprofundado desse material didático leia-se o texto de Valente (2014).

${ }^{20}$ Ver Valente (2014).
} 
$\mathrm{Na}$ esteira da vanguarda paulista de organização do ensino primário, da criação do modelo dos grupos escolares, está presente também o modo escolhido para concretizar os ensinos de aritmética: as Cartas de Parker. "Trabalhar primeiro no concreto" desloca-se para o trabalhar tendo por referência o concreto, os desenhos e figuras contidos nas Cartas. Há, neste aspecto, um verdadeiro ponto de inflexão. O concreto como representação dada pelos mapas, cartas, desenhos.

Décadas mais tarde, concretizar passa a ter outro significado: não se trata mais de realizar uma associação entre as coisas do mundo e o signo matemático, tampouco criar desenhos, figuras representativas do mundo físico a serem associadas aos objetos matemáticos. Será preciso materializar os próprios signos, o saber sistematizado diretamente: os chamados blocos lógicos (peças geométricas em forma de quadrados, retângulos, triângulos e círculos) cumprem essa função e nada representam do mundo físico, intentam representar o mundo matemático, os seus objetos. Os blocos lógicos revelam-se como alternativa do "trabalho no concreto", agora tendo por significado as bases teóricas estabelecidas por Jean Piaget e reelaboradas por seus seguidores para o ensino de matemática nos primeiros anos escolares. Destaca-se, dentre eles, Zoltan Dienes (“Através de múltiplas atividades, os alunos se encontrarão em presença de coleções de objetos concretos (blocos, bolas, cartas, entre outros”) [...].

De qualquer modo, a questão pedagógica central envolve um desafio didático para o ensino de aritmética, no caso do curso primário, válido, porém, para todas as outras rubricas escolares: a passagem para as referências sistematizadas de um saber. Em tempos da vaga intuitiva essa passagem é concebida por meio das coisas. Assim, é preciso concretizar, é preciso trabalhar primeiro no concreto...

\section{Agradecimento}

O autor agradece o apoio do Conselho Nacional de Desenvolvimento Científico e Tecnológico $(\mathrm{CNPq})$ para o desenvolvimento desta pesquisa.

\section{Referências}

BARBOSA, R. Reforma do ensino primário e várias instituições complementares da instrução pública. Obras completas de Rui Barbosa. Rio de Janeiro: Ministério da Educação e Saúde, 1946. v. 10, tomo 2.

BRITO, J. Cartas de Parker: para o ensino de arithmetica nas escolas primarias. Revista de Ensino, São Paulo, v. 1, n. 1, p. 1-46, 1902. Disponível em: < http:// repositorio.ufsc.br/ xmlui/handle/123456789/98842>. Acesso em: 27 jun. 2017.

CATANI, D. B.; BASTOS, M. H. C. (Org.). Educação em revista: a imprensa e a história da educação. São Paulo: Escrituras, 1997. 
CATANI, D. B.; VICENTINI, P. P.; LUGLI, R. S. G. O movimento dos professores e a organização da categoria profissional: estudo a partir da imprensa periódica educacional. In: CATANI, D. B.; BASTOS, M. H. C. (Org.). Educação em revista: a imprensa periódica e a história da educação. São Paulo: Escrituras, 1997. p. 77-92.

CATANI, D. B. A imprensa periódica educacional: as revistas de ensino e o estudo do campo educacional. Educação e Filosofia, Uberlândia, v. 10, n. 20, p. 115-130, jul./dez., 1996. Disponível em: <http://www.seer.ufu.br/index.php/EducacaoFilosofia/article/ viewFile/928/842>. Acesso em: 19 nov. 2016.

CAVALCANTE, A. Nos etiam pro causa nóstra pugnamus. Revista do Ensino Primário, [Salvador], v. 1, n. 1, p. 1-9, 1892. Disponível em: <https://repositorio.ufsc.br/ handle/123456789/129725>. Acesso em: 27 jun. 2017.

CELESTINO, P. O ensino de arithmetica I. Revista do Ensino Primário, [Salvador], v. 1, n. 8, 1893a. Disponível em: <https://repositorio.ufsc.br/xmlui/ handle/123456789/129730>. Acesso em: 27 jun. 2017.

. O ensino de arithmetica III. Revista do Ensino Primário, [Salvador], v. 1, n. 11, p. 211-212, 1893b. Disponível em: <https://repositorio.ufsc.br/xmlui/ handle/123456789/129733>. Acesso em: 27 jun. 2017.

CHARTIER, R. A história cultural: entre práticas e representações. Rio de Janeiro: Bertrand: Difel, 1990.

CHERVEL, A. História das disciplinas escolares: reflexões sobre um campo de pesquisa. Teoria \& Educação, Porto Alegre, v. 2, p. 177-229,1990.

DIENES, Z. P.; GAULIN, C.; LUNKENBEIN, D. Un programme de mathématque pour le niveau élémentaire. Bulletin de l'AMQ, Québec, n. 3, p. 29-51, automne-hiver 1969.

A ESCHOLA PUBLICA, São Paulo, v. 1, n. 1, 1893. Disponível em: < https://repositorio. ufsc.br/xmlui/handle/123456789/133603>. Acesso em: 27 jun. 2017.

FERNANDES, A. L. C. O campo pedagógico no Brasil no final do século XIX: lugares, pessoas e instituições na construção de uma nova sociedade. In: SIMPÓSIO NACIONAL DE HISTÓRIA, 27., 2013, Natal. Anais... Disponível em:. < http://www.snh2013.anpuh. org/resources/anais/27/1364922744_ARQUIVO_TextoAnaLuciaCFernandesAnpuh2013. pdf>. Acesso em: 27 jun. 2017.

GRANDO, C. M. Relação entre concreto, formal e abstrato para a construção dos conceitos matemáticos. In: Anped-sul, 1999. Disponível em: < http:/ /www.portalanpedsul.com.br/ admin/uploads/1999/Educacao_E_Trabalho/Trabalho/09_14_49_RELACAO_ENTRE_ CONCRETO_FORMAL_ABSTRATO_PARA_CONSTRUCAO_DOS_CONCEITOS_ MATEMATICOS.pdf $>$. Acesso em: 12 mar. 2016.

JULIA, D. A cultura escolar como objeto histórico. Revista Brasileira de História da Educação, Campinas, v. 1, n. 1, p. 8-43, jan./jun. 2001.

KAHN, P. La leçon de choses: naissance de l'enseignement des sciences à l'école primaire.

Paris: Presses Universitaires du Septentrion, 2002. 
MAIA, L. S. L. O que há de concreto no ensino da matemática? Zetetiké, Campinas, v. 9, n. 15/16, 2001.

NACARATO, A. M. Eu trabalho primeiro no concreto. Revista de Educação Matemática, São Paulo, v. 9, n. 9-10, p. 1-6, 2005.

PAIS, L. C.; FREITAS, J. L. M. Aspectos históricos do ensino do cálculo mental na instrução primária brasileira (1848-1910). Acta Scientiae, Canoas, v. 17, p. 113-133, 2015.

PINTO, A. A. Contribuições da imprensa periódica especializada para os estudos em história da educação: a revista A Eschola Publica e as disputas pela hegemonia do campo educacional paulista (1893-1897). Fronteiras, Dourados, MS, v. 10, n. 18, p. 95-118, jul./dez. 2008.

SANTANA, E. C. A voz dos professores baianos no início da República: a Revista do Ensino Primário (1892-1893). Revista HISTEDBR, Campinas, n. 36, p. 70-82, 2009.

Disponível em: <http://www.histedbr.fe.unicamp.br/revista/edicoes/36/art06_36.pdf >. Acesso em: 27 jun. 2017.

SILVA, J. F. V. Observação aos professores ou adjuntos que se occupam do ensino da arithmetica nas classes elementares das escolas do $1^{\circ}$ gra’o. Revista Pedagógica, [Rio de Janeiro],1893. Disponível em: <https://repositorio.ufsc.br/xmlui/ handle/123456789/130209>. Acesso em: 27 jun. 2017.

SOUZA, R. F. Alicerces da pátria: história da escola primária no Estado de São Paulo (1890-1976). Campinas: Mercado das Letras, 2009.

THOMPSON, O. Arithmetica elementar. A Eschola Publica, São Paulo, v. 1, n. 1, p. 5-6, 1893. Disponível em: <https://repositorio.ufsc.br/xmlui/handle/123456789/133603>. Acesso em: 27 jun. 2017.

VALENTE, W. R. Lourenço Filho e o moderno ensino de aritmética: produção e circulação de um modelo pedagógico. História da Educação, Porto Alegre, v. 18, n. 44, p. 61-77, 2014. 